\title{
Humanitarian Logistics: Enhancing the Engagement of Local Populations
}

\author{
A conceptual paper by: \\ Mr Allan Sheppard, Griffith University, Australia \\ Dr Peter Tatham, Griffith University, Australia \\ Dr Ron Fisher, Griffith University, Australia \\ Dr Rodney Gapp, Griffith University, Australia
}




\title{
Humanitarian Logistics: Enhancing the Engagement of Local Populations
}

\begin{abstract}
Purpose - The purpose of the paper is to identify how local populations, particularly at the municipal and village levels, can enhance their capacity to prepare and respond more effectively and efficiently to the logistic challenges that they face in the aftermath of a natural disaster.

Design/Methodology/Approach - Using a phenomenological approach, a qualitative research study was conducted from an interpretative, constructivist perspective. Through a series of semi-structured interviews the researchers gathered stories about the experiences of local responders at municipal level in the capital city region of the Republic of the Philippines in the aftermath of a specific natural disaster event (Typhoon Ondoy - September 2009). A number of key differences between the espoused strategies expressed in disaster management legislation and the actual experiences of local people on the ground were identified and, as a result, a conceptual model was developed that, if implemented, would enhance the capacity of local populations to prepare and respond in a more efficient and effective manner.

Findings - Results from the study indicate that the ability of local populations to contribute to the logistic preparation and response processes has been considerably undervalued and underutilised. A revised model is therefore developed that better incorporates their potential contribution to the management of both the demand and supply sides that would lead to swifter, more accurate, and more efficient logistic response mechanisms.

Originality/value - The developing canon of humanitarian logistic literature has, to date, been relatively silent on the subject of the contribution of the local population to the overall logistic management challenge. The paper provides important insights into the issues on which the government of a developing country could usefully focus attention in their approach to natural disaster preparedness and response, and it offers a conceptual model for future testing and evaluation.
\end{abstract}

Keywords - Natural disaster, Preparedness, Response, Humanitarian Logistics, Coordination, Local Populations

Paper Type - Conceptual paper 


\section{Introduction}

The 2004 earthquake and tsunami in South East Asia was instrumental in triggering a significant increase amongst both academics and practitioners in research into ways in which the management of the logistic preparation and response to natural disasters could be enhanced and improved (Balcik and Beamon, 2008; Kovács and Spens, 2007; Kovács and Spens, 2011). The resultant body of literature has highlighted multiple challenges at strategic, operational and tactical levels including (but not limited to): inter-agency coordination, training and retention of qualified logistics personnel, use of technology for information and communications management, and performance measurement systems (Kovács and Spens, 2011; Kunz and Reiner, 2012). However, one area that has yet to feature within the literature relates the consideration of how logistic practices might become more relevant to the needs of local people on the ground at municipal and village levels in the developing world, and how such populations might engage in the logistics preparation and response processes and, thereby, improve their effectiveness and efficiency.

In particular, it is noted that humanitarian agencies generally suffer from a heavy turnover of field logistics staff (Van Wassenhove, 2006), and this is reported to be as high as 80 per cent annually (Thomas, 2003; Thomas and Kopczak, 2005). As a result, many agencies struggle to maintain sufficient suitably trained and experienced personnel to be able to respond effectively to natural disasters, and this conceptual paper argues that this problem could be mitigated by increased involvement of the local populations. Such a locally-focused approach to the delivery of a post-disaster logistic response requires different ways of working (Ethike Media, 2012), and it is these new approaches that are explored using a case study of the Republic of the Philippines (RP) and its response to Typhoon Ondoy (internationally known as Ketsana) that severely impact the country on 26 September 2009.

The study identifies how local populations can enhance their capacity to respond effectively to natural disasters, particularly at the municipal and village levels, with an emphasis on the final logistics stage - the last mile of delivery - when disaster relief is provided directly to the beneficiaries by local agencies. The research identifies gaps that exist between the espoused strategies for natural disaster management developed at national government level (what should be done) and the actual actions experienced on the ground from the perspective of the local people. As a result, a theoretical model has been developed to demonstrate how those gaps could be bridged, and to provide the answers to the research question: How, in developing countries, can local populations contribute to an effective post-disaster logistic response?

To achieve this aim, the paper will first set the context of humanitarian logistic response in a developing country and will briefly reflect on some of the key challenges in achieving improved engagement with local populations. It will then discuss the theoretical approaches offered within the logistic and supply network management literature, before offering a conceptual model that has the potential to deliver improved outcomes for those affected by such natural disasters.

\section{Setting the Context}

The challenge of achieving an efficient and effective humanitarian logistic response has been increasingly well documented, not least through the medium of the Journal of Humanitarian Logistics and Supply Chain Management. However, in light of the focus of this paper, it is appropriate to emphasise a number of issues that all have a considerable impact on the ability of a developing country such as the RP to achieve improved outcomes and the associated 
building of an indigenous capacity to prepare and respond to natural disasters - and, in particular, its logistic component.

Planning and provision of the right kind of assistance, at the right time and in the right quantities to meet uncertain demand is the main focus of humanitarian agencies during the post-disaster (or response) phase in natural disasters. Agencies must deal with issues generated by the type and location of the disaster, emergency funding, effective coordination, information management, training, performance measurement and being able to record and apply lessons identified from previous disasters in their operations.

\subsection{Location of the research}

Whilst there has been a welcome reduction in the number of natural disasters recorded worldwide (a total of 302 in 2011 compared with a decade average of 384), the Asian region experienced some $45 \%$ of the 2011 total global disaster count, with $85 \%$ of world disaster casualties and $75 \%$ of the global economic damage - albeit the latter statistics were influenced by the impact of the Tōhoku earthquake and tsunami (CRED, 2012).

Nevertheless, given that the RP is a developing country that is particularly vulnerable to a range of natural disasters, including earthquakes, volcanic eruptions and flooding caused by an average of some 20 typhoons each year, it represents an appropriate location to use as the basis for the research into the potential for improved local logistics capacity building.

\subsection{The Humanitarian Logistic Actors}

Whilst the focus of this research is at the municipal and village level, any proposed changes must be set in the context of the broad range of actors involved in humanitarian logistics activities which, as indicated in Table 1, includes Governments, international and national donors, aid agencies, international non-government organisations (INGOs), non-government organisations (NGOs), logistics service providers and the national (and, for major disasters, international) police and armed services (Branczik, 2004; Kovács and Spens, 2007).

However, whilst it is accepted that in many cases the beneficiaries cannot be considered humanitarian logistics actors per se as they do not directly shape demand (Kovács and Spens, 2008), it is argued that the local populations that have not been directly affected by a given disaster event also have a significant, but less well researched, role to play and are, therefore, key stakeholders in the overall humanitarian logistics process (Newport and Jawahar, 2003; Oloruntoba, 2005; Perry, 2007).

\subsection{Coordination}

The capacity of local populations to make a more effective response to natural disasters can be enhanced by ensuring effective coordination systems between these various actors are put into place. But, with so many actors involved in disaster response, coordination is seen as a major concern and one of the most pressing world-wide issues in humanitarian logistics operations (Tomasini and Van Wassenhove, 2009; Chatterjee et al., 2010; Jahre and Jensen, 2010). In this regard, and in light of the transient nature of the international relief effort, the local population is perceived to have a vital role to play as the guardian of the specific knowledge (in terms of both the demand and supply sides of the logistic challenge) that can be leveraged to achieve the desired reduction in response times and the maximisation of the distribution of relief goods.

\section{INSERT TABLE 1 ABOUT HERE}




\section{$2.4 \quad$ The Logistic Funding System}

It is increasingly accepted that an appropriate application of the principles of commercial agile supply chain management will help to improve the operational efficiency and effectiveness of humanitarian logistic operations (Christopher and Tatham, 2011). This is particularly the case at a time when humanitarian agencies are operating with reduced resources in the aftermath of the Global Financial Crisis and against the rising demands from both natural disasters and complex emergencies. Given that logistics (purchasing, transporting, warehousing and delivering materiel) accounts for an estimated 60-80 percent of the income of humanitarian agencies (Majewski et al., 2010; Tatham and Pettit, 2010), clearly actions that will help reduce costs and contribute to more successful outcomes are to be welcomed. Unfortunately, however, the adoption of an agile approach, with its inherent incorporation of contingency against unforeseen events, implies that donor governments and organisations must be prepared to pay what is, in effect, an insurance premium which, like all such premiums, may ultimately seen to have been nugatory expenditure.

Equally unfortunately, the scope of humanitarian activities can be adversely affected by the funding systems upon which aid agencies depend (Stoddard, 2008). Indeed the current funding mechanism has been blamed for many of the inefficiencies in humanitarian operations as they can 'directly and indirectly affect the effectiveness and efficiency of disaster response' (Wakolbinger and Toyasaki, 2011, p34). Not least is the reality that the current practice is, in the main, for donors to provide funding as and when the disaster occurs, rather than during the pre-disaster phase. This is well illustrated by Jahre and Heigh (2008) in their case study of the IFRC in which they clearly demonstrate that relatively little funding is provided by donors for longer-term preparedness programmes compared to high levels of short-term disaster response funding. A clear outcome of this feast or famine situation is that it often leads to hasty (and not necessarily economic) purchasing decisions as well as competition among agencies for limited resources such as transport or warehousing that, in turn, leads to higher unit prices. However, appropriate and meaningful engagement with local communities is unlikely to be effective in the immediate, and frequently chaotic, aftermath of a disaster. Such activities need to be undertaken when individuals and organisations are not faced with the pressures of decision making under stress and uncertainty, but rather when the benefits of alternative approaches can be considered in a rational and measured way.

\section{Theoretical Underpinnings}

As outlined above, the logistic preparation and response to uncertain future events such as rapid onset natural disasters can be considered as an extreme example of the need for an agile (Christopher, 2011) or fully flexible (Gattorna, 2010) supply network. Thus, Christopher and Holweg (2012), drawing on many of the underpinning concepts of Teece's Dynamic Capabilities Model (Teece and Pisano, 1994), argue that the necessary structural flexibility to be able to combat the uncertainties of a turbulent business environment include: dual sourcing, asset sharing, postponement and outsourcing.

In practice, and as demonstrated by the Jahre and Heigh (2008) IFRC case study, the development of postponement and speculation strategies and other broader ways in which the management of the flows of material, information and human resources can be improved, are already topics that are under consideration by academics and practitioners alike. Thus, Jahre and Heigh (2008) advocate the pre-positioning of generic relief goods in regional stores close to vulnerable areas in order to help to ensure their availability for timely delivery. Such prepositioning of basic relief goods can also address the issue of uncertainty or limitations of 
local supply which often occur in emergency situations (Jahre and Heigh, 2008; GHD 2012). Self-evidently, such regional warehouses should be located as close to vulnerable locations as possible, whilst maintaining a safe distance to avoid them being adversely impacted by a disaster event (Balcik and Beamon, 2008). However, taking this one stage further, and as will be explained in greater detail below, the authors of this paper suggest that such warehouses could also accommodate the regional emergency headquarters and operational control facilities for local disaster management coordination, as well as providing a centre for disaster management training at the regional level. This co-location of activities will help to ensure both the security and serviceability of the relief goods as well as provide opportunities to logistics and response teams more generally to become familiar with their handling and operation.

Building on the work of Jahre and Heigh (2008) and integrating it with the theoretical work of Bowersox and Closs (1996), it is suggested that a standard selection of generic relief supplies could be pre-positioned (speculation) with logistic (ie last mile distribution) action held off (postponed) until the occurrence of a disaster event. Thus, assembly and storage of standard family kits and other key requirements can be carried out in the preparedness phase, ready for pre-disaster distribution. Final packaging and labelling (form) would be completed once the demand is clearly identified (time) from the findings of the beneficiary needs assessment activities. Transportation can then provided for distribution and delivery of relief goods to the beneficiaries' locations (place).

As demonstrated by Everywhere et al. (2011), and contrary to much of the prevailing literature, it is possible to use traditional methods from commercial literature to forecast with reasonable accuracy the demands for non-food items (NFI) in the aftermath of a disaster. As a result, a standard selection of relief goods could include pre-packaged units of generic NFI such as shelter materials, tarpaulins, blankets and sealed medical kits, together with nonperishable food items including canned goods (Bozskurt and Duran, 2012). Perishable items such as fresh food and water and other medical supplies could be provided from donations or through locally-contracted purchasing arrangements in the response phase once demand has crystallised. However, as indicated above, it is strongly argued that the development of such a dynamic and flexible logistic response would greatly benefit from close engagement with the local population who will be able to provide situational specific advice and expertise. This, in turn, would lead to more effective outcomes such an increased speed of supply and distribution from local storage warehouses, and a reduction of lead times and transportation costs. Involving local populations in these activities would also avoid the need for international agencies to provide relatively expensive and less timely management through expatriates for the duration of the disaster event as well as helping the indigenous teams improve their own expertise by 'learning through doing'.

\section{A Changing Approach to Preparedness and Response}

According to Dr Randolph Kent (2102), the current approach to natural disaster response in which the international humanitarian community assumes that it has exclusive expertise and capacity for disaster response, is no longer appropriate and should be seen as 'old time thinking' (Kent and Burke, 2011). Furthermore the concept that 'west is best' will become increasingly invalid as national authorities in developing countries continue to move towards the rejection of Western solutions to the prevention of, preparation for, and response to future catastrophes in favour of locally developed models (Kent, 2012). However, in order for such an approach to become effective, local populations will have to be provided with the 
necessary support to enable them to manage disaster preparedness and response in their own right.

In practice, much of this support can come from within the ranks of the local populations themselves through their engagement with the commercial sector which, as demonstrated earlier, is well placed to provide expertise to support and enhance the logistic preparation and response. In addition, international humanitarian institutions would continue to provide support through pooling their knowledge and expertise although, unlike the current situation where there is a considerable degree on inter-agency competition, the development of communities of practice would be indicated as a much more efficient and effective approach (Wenger and Snyder, 2000; Wenger, 2006). From a purely financial perspective, investment in the local populations' capacity to manage disaster preparedness and response for themselves would have a number of beneficial outcomes including the achievement of a swifter and more efficient response (Ethike Media, 2012). The necessary funding could be, at least in part, delivered through savings on expatriate fares, transportation, the provision of specialist equipment etc.

One further solution to the lack of indigenous capacity could well lie in greater involvement of the local private sector organisations in the preparedness phase and between disasters as recommended by Tomasini and Van Wassenhove (2009). In areas such as the RP that are frequently beset by a significant number and range of natural disasters, a semi-permanent response supply network could be established, with private sector organisations being involved as partners in donating money, goods and expertise to the local population both in improving levels of preparedness as well as during the actual response phase. In this respect, the private sector has a clear interest in staying in business and surviving during and after natural disasters such as typhoons, which do not discriminate but impact all levels of society including the commercial organisations themselves. Hence, greater involvement of private sector organisations, particularly in the preparedness phase, would be of significant mutual benefit (Van Wassenhove et al., 2007; APEC, 2010).

However, for such a revised approach to be implemented successfully, national governments need support to improve their preparedness and response processes - especially in the vital area of logistics - and the associated training and development programmes that build on their pre-existing knowledge and skills. It is the authors' contention that it is time to pass the baton of responsibility for the preparation and response to natural disasters from the international humanitarian community providers to the local populations and, thereby, to empower them to develop and implement an effective, sustained, and sustainable response. The next section will offer a high level blueprint of how this might be achieved in the logistic domain.

\section{Putting the Theory into Action}

As indicated in the introduction to this paper, the conceptual model that will be exposed in this section has been developed in the light of lengthy field research that took place in the area affected by Typhoon Ondoy. From the analysis of the accounts of the research participants, a clear picture of considerable shortfalls in preparedness (particularly at the municipal level) has been identified, but which can be remedied through implementation of the proposed model. The proposed approach has drawn heavily on that currently in place within a regional neighbour (Australia) that is also beset by multiple natural disasters including severe flooding, bush fires, cyclones and extremely high temperatures. 
The proposed model has, in particular, been designed to take into account the requirements of the 2010 Philippine Disaster Management Act (PDMA) which was enacted in the aftermath of Typhoon Ondoy. Where appropriate, the current arrangements under the Act have been retained, whilst the change proposals are designed to deliver an enhanced approach to logistic preparedness and delivery. The major change proposed is that the operational decisionmaking and control is moved from the central strategic levels of management to a physical and conceptual location nearer to where the operations are carried out - i.e. at the Municipal or City level. Under such an approach, the National Disaster Risk Reduction Management Council (NDRRMC) would retain its existing role as the central authority responsible for implementing the requirements of the Act, but the actual operational control would be devolved. By the same token, the roles and responsibilities of the Regional Disaster Risk Reduction Management Councils (RDMCC) would be retained with some suggested additions.

It should be noted that the proposed approach has been developed using the National Capital Region of Manila as an example. As a result, the Provincial level (which is incorporated in the National structure laid out in the PDMA) is not included in the model - indeed, in reality, it is suggested that the inclusion of the Provincial level simply adds another reporting level, which can, in fact, complicate the operational interaction between the national, regional and municipal/city levels. The resultant structure is shown in Figure 1 which includes a summary of the functions associated with each organisational level.

\section{INSERT FIG 1 ABOUT HERE}

\subsection{The National Disaster Risk Reduction Management Council}

As required by the PDMA, the NDRRMC is directly responsible to the RP Government and is in overall control of the response to a disaster. The NDRRMC also provides a liaison point with international agencies such as UN humanitarian organisations. The NDRRMC also manages a 24-hour Operations Centre which provides overall coordination of disaster response as well as direct communication with appropriate authorities to facilitate early warning or notification of an impending or approaching emergency situation to regional and municipal authorities and to the general public.

\subsection{Local Disaster Risk Reduction Management Councils (LDRRMC).}

At the regional level, it is proposed that the LDRRMC would develop and operate a logistics cluster with the membership (in line with the requirements of the PDMS) including representatives from appropriate local governmental organisations, NGOs, utility suppliers, emergency services and others. In order to avoid duplication and inefficiency, specific functions would be allocated to cluster members based on their particular areas of expertise. Thus, for example, local representatives of the RP Red Cross might accept the responsibility to provide tracking and tracing services and administration of evacuation centres, in conjunction with the appropriate government departmental representatives (such as education where schools are used for evacuation centres).

\subsection{Centre of Excellence in Disaster Management Training}

Given the importance of developing the necessary skills and expertise in both general disaster management and, specifically, in logistics, it is proposed that a National Centre for Excellence in Training for Disaster Management be established and co-located with the National Disaster Management Operations Centre (NDMOC). This Centre of Excellence could be also act as a hub for South East Asia so that neighbouring countries might send their 
staff to attend high level disaster management training. In this way, methods and approaches that are appropriate to the SE Asian (as distinct from, say, the US, UK or EU) context can be developed and implemented on a regional basis. The content of the certificate-level training programmes would reflect the strategic approaches to disaster management developed by the NDRRMC, and be presented by accredited tertiary providers such as the Ateneo de Manila, or the University of the Philippines with the target audience being high ranking executives and senior managers from governmental and commercial organisations. The work of the training centre would be supported by a Community of Practice made up of invited national and international experts in disaster management and logistics that would assist in, and complement, the design and delivery of the high level education programmes.

\subsection{Regional Training Centres}

Paralleling the national structure, Regional Training Centres could be developed and colocated with Regional Disaster Management Operations Centres (RDMOC) in order to provide bespoke courses for attendees from local government units (LGUs), NGOs and the private sector. Such programmes would include courses such as the Certification in Humanitarian Logistics (CHL) offered by the Logistics Learning Alliance in conjunction with Fritz Institute. Although the CHL is currently taught in distance learning mode, it could be relatively easily adapted to enable provision in a classroom or seminar situation. Importantly, it is argued that the audience for these programmes would be appropriate individuals who, in addition to their primary operational role at the regional level could, in turn, conduct training of municipal/city disaster management teams - i.e. making use of the 'train the trainer' concept.

\subsection{Municipal/City Training Centres}

In the same way as at the national and regional levels, it is proposed that Municipal/City Training Centres be co-located with the Municipal/City Disaster Operations Centres. Trainers from the regional levels would cascade the training down to the Municipal/City level where the content would have an operational logistics focus related to the "nuts and bolts" of disaster response in their particular location. This would include key elements of the overall logistics process such as beneficiary needs assessment, warehouse operation (including inventory management), transport and distribution, management of evacuation centres, and ethical procurement processes including sourcing of relief goods at local level. Importantly, although the syllabus for these courses would be standardised, the intention would be to tailor these to take account of local conditions and practices. Thus, an appropriate balance would be achieved between cascading the programme from National through Regional to Municipality/City level (thereby helping to ensure the consistency of the approach and message) whilst, at the same time, accepting a degree of 'tolerable variation' to take account of local circumstances.

\subsection{Storage and Distribution of Disaster Relief Supplies \\ 5.6.1 National Warehouses}

As discussed above, the development of pre-packaged units of relief goods is perceived, from both a theoretical and practical perspective, to be a key element in the improvement of the logistic support for disaster preparedness programmes. Thus, it is proposed that three national warehouses be established in strategic locations such as Subic Bay Management Authority (SBMA), Cebu, and Davao. The choice of these locations reflects the fact that each has access to a seaport and an international/domestic airport within a reasonable flying time to Manila whilst, in the case of SBMA, there is also good highway access to the capital. Furthermore, the nomination of three such locations is designed to provide a contingency to 
ensure that, in the event of an emergency which may affect one or more of the warehouses, then continuity of supply can be provided by either or both of the others - in other words, an example, of the dual-sourcing approach suggested by the agile logistics theory.

Disaster relief goods that could sensibly be stored in the national warehouses would include bulk supplies of standard items such as shelter materials, tarpaulins, blankets and tents, together with sealed food items with relatively long shelf life such as high-energy biscuits. Other NFIs could include non-perishable medical and hygiene supplies. The national warehouses would provide the buffer stock to replenish regional warehouses as necessary whilst also helping to ensure the ready access to the core stock items without having to resort to costly and risky last minute procurement and transport into the country.

\subsubsection{Regional Warehouses}

In a similar way, it is proposed that a network of regional warehouses be established at strategic locations close to vulnerable areas, although at a safe distance to avoid the warehouse being rendered inoperative by the emergency. Regional warehouses can be used to pre-position bulk supplies of standard NFI to complement the supplies available in the municipal/city warehouses. Clearly the actual number and location of such warehouses will require further research which would take into account both the specific threats (e.g.

vulnerability to typhoons, earthquakes, flooding, etc.), as well as the existing road, sea and air links. However, in practice, many examples of the resolution of such location problems exist - for example through the analysis of researchers such as Balcik and Beamon (2008).

\subsubsection{Municipal/City Warehouses}

Existing warehouses that are established in municipalities and/or cities could be utilised as centres to supply humanitarian agencies with disaster relief goods. In this respect, it is strongly argued that, not least in order to prevent competition between agencies for scarce resources, all disaster relief goods should be pooled and that each of the agencies engaged in relief goods acquisition and distribution should use this as their primary source. Allocation of relief goods would be made based on the results of a fully-coordinated and shared needs assessment carried out by members of the municipal/city LDRRMC, operating as a local cluster as discussed below. Inventory for such warehouses would be replenished from the regional/national level as required. When agencies receive specific donations from their own sources, such as in church groups who receive donations from parishioners, these can be utilised at the discretion of that agency and would not necessarily be included in the pool stock. However, as a general rule, individual and/or group donors would be encouraged to provide donations direct to the municipal/city warehouse rather than to the individual agency.

\subsection{Emergency Response Teams}

One of the critical requirements of an effective emergency response is the availability of teams of well-trained and suitably equipped personnel who can move into action at short notice or in response to early warnings according to the location and type of the disaster event. The analysis of the research data identified that there was a shortage of such trained personnel and that the early post-disaster response was frequently carried out by untrained volunteers from the local population. In addition to the training structure discussed above, it is therefore proposed that an emergency response structure be created. This approach draws heavily on the highly successful model of the State Emergency Service in Queensland, Australia (SES Queensland, 2012) with strategic regional control at the RDRRMO and local operational responsibility residing at municipal/city level. 


\subsubsection{Municipal Emergency Response Teams (MERT)}

The model calls for the establishment of a Municipal Emergency Response Team (MERT), comprising trained volunteers and based in each municipal or city emergency headquarters. Recruits for the MERT would be sought from each of the townships under the jurisdiction of the municipal or city authority, thereby helping to ensure that local knowledge and expertise is retained and shared. MERT members would be given full training in preparedness and response to a number of emergency situations, including typhoons, floods, storms, earthquakes, landslides, and in supporting other emergency services, with a specific focus on the logistic-related elements of their role. In order to ensure continuity of competence, it is suggested that there is likely to be a need for MERTs to meet on a regular basis for training, say on weekends, in a similar manner to Armed Forces reservists.

MERT members would be equipped with personal protective clothing and equipment such as safety glasses, hard hat and gloves. Each member of the team would be supplied with a SMART phone as a means of disseminating operational information and to facilitate emergency call outs. Each MERT would manage and maintain its own equipment such as trucks and boats, and could be co-located with, for example, the local Fire Department Headquarters. Training in equipment maintenance could be provided locally with the cooperation of private sector transport companies or commercial vehicle service stations. MERT members would be afforded full state recognition, and employers would be expected to release the volunteers on full pay from the normal workplace to attend emergency and training situations as part of the team response.

\subsection{Logistics Management Information Systems}

As is clear from both the theoretical literature supporting the concept of logistic agility, as well as from practical experience in the commercial world following the development of data capture systems such as supermarket checkout data scanners, the provision of an integrated logistics management information system (MIS) is a fundamental requirement for both the preparedness and response phases of natural disaster management. Not least of all, the adoption of a single software application (such as the HELIOS system that is being pioneered by a consortium of international NGOs) (Blansjaar and van der Merwe, 2011) has the added benefit of helping to drive commonality of logistic processes. Whilst this requirement might be relatively easily met across the government controlled elements of the overall NDRRMC system, the planned use of common municipality/city warehouses implies that the whole spectrum of responding agencies (such as nationally and locally-based NGOs) should use a common system in order to facilitate the integrated exchange of information, such as shared needs assessments, damages reports, relief goods pipeline tracking availability of pooled resources, etc. In short, the use of such a system is designed to facilitate the development and implementation of a common humanitarian logistic picture (CHLP) such as was first attempted by the US forces in the aftermath of the 2010 Haiti earthquake (Vohr, 2011) .

\subsection{Summary}

Throughout this paper it is argued that, in order to improve the logistics (and indeed broader) preparedness and response to natural disasters, a greater involvement of local populations would lead to greater efficiency and effectiveness. This is particularly true of developing countries where a significant resource exists that remain relatively untapped, and yet which is both willing and able to make a major contribution to improvements in current practice. However, such a major engagement with the local population implies a significant change to existing practice in which the involvement of international (western) 'experts' is the norm in any major disaster. Thus, enabling national governments and the local people to manage the 
preparedness and response activities for themselves, requires a systemic change in relation to funding, training, and command and control across the whole spectrum of logistic functions.

Nevertheless, a new approach of this nature would recognise and acknowledge the abilities of local populations in developing countries to provide for and manage their own disaster responses, rather than assume that expatriate humanitarian agencies are the best or, indeed, the only, answer. The proposed conceptual model, which has been developed in the wake of extensive field work, offers a high level vision of how such a new paradigm might be implemented in a country such as RP. In particular, it is designed to bring together the skills and capacities of the local population through strategic coordination at the executive level and operational coordination at the municipal level.

Decentralising operational decision-making closer to the location of the natural disaster event would enable a more timely and effective response, whilst pooling of resources such as relief goods would reduce the level of competition between humanitarian agencies for resources, facilitating greater financial efficiency and helping to ensure improved value for money for the donors. The implementation of the CHLP concept which captures and displays the results of joint and integrated needs and damage assessments, consequential estimates of levels and locations of demand, current stock location and incoming supplies, is a key component that would help to reduce the imbalances between supply and demand. Whilst a more coordinated effort to provide standardised and tailored training, and the provision of the emergency response teams, would enable resources to be used more efficiently and effectively.

In conclusion, it is strongly argued that implementing the proposed model would enhance the capacity of the local populations to provide a vastly improved logistic response to natural disasters. The desire and willingness for local governments to reduce their dependence on international response would also be well served, through a well-resourced and wellcoordinated response provided through the increased capacity of the local population.

\section{References}

APEC. (2010), "Public-Private Partnerships and Disaster Resilience", Report from APEC Workshop on Public-Private Partnerships and Disaster Resilience, Bangkok, Thailand, 24-29 August

Balcik, B., and Beamon, B. (2008), "Facility location in humanitarian relief", International Journal of Logistics: Research and Applications, Vol. 11 No. 2, pp. 101-121.

Blansjaar, M., and van der Merwe, C. (2011), "The importance of information technology in humanitarian supply chains: opportunities and challenges in the Helios project" in Christopher, M.G., and Tatham, P.H. (eds), Humanitarian Logistics. Meeting the Challenge of Preparing For and Responding to Disasters” Kogan Page Limited, London, pp. 47-64.

Bowersox, D., and Closs, D. (1996), Logistical management: The integrated supply chain process, McGraw-Hill Companies, New York, NY.

Bozkurt, M., and Duran, S. (2012), "Effects of natural disaster trends: A case study for expanding the pre-positioning network of CARE International", International Journal of Environmental Research and Public Health, Vol. 9, pp. 2863-2874. 
Branczik, A. (2004), "Humanitarian Aid and Development Assistance", available at: www.beyondintractability.org/essay/humanitarian.aid/htm (accessed 10 October 2012).

Chatterjee, A., Gupta, D., and Jain, N. (2010), "Coordination of disaster response: Potential and challenges from Indian experiences", Red $R$ India, available at:

http://www.redr.org.in/uploads/Coordination_of_Disaster_Response.pdf (accessed 8 August 2012).

Christopher, M.G. (2011), Logistics \& Supply Chain Management $\left(4^{\text {th }}\right.$ Ed), Pearson Education Ltd, Harlow, UK.

Christopher, M.G., and Tatham, P.H. (2011), "Introduction" in Christopher, M.G., and Tatham, P.H. (eds), Humanitarian Logistics. Meeting the Challenge of Preparing For and Responding to Disasters", Kogan Page Limited, London, pp. 1-14.

Christopher, M.G. and Holweg, M. (2012), " "Supply Chain 2.0”: Managing supply chains in the era of turbulence, International Journal of Physical Distribution and Logistics

Management, Vol. 41 No. 1, pp. 63-82.

CRED. (2012), “CRED Crunch 2011 Disasters in Numbers”, available at: http://www.cred.be/sites/default/files/CredCrunch27.pdf (accessed 12 May 2012).

Ethike Media. (2012), "New order rejects traditional view of disaster response", available at: http://hu-online.org/index.php/j-stuff/category-blog/349-new-order-rejects-traditional-viewof-disaster-response (accessed 2 June 2012).

Everywhere Humanitarian Response and Logistic Services, Jahre, M., and Navangul, K.A. (2011), "Predicting the unpredictable - demand forecasting in international humanitarian response", Proceedings of NOFOMA, Harstad University College, 9-10 June.

Gattorna, J. (2010), Dynamic Supply Chains (2 ${ }^{\text {nd }}$ Ed), Pearson Education Ltd, Harlow, UK

GHD. (2012), "23 Principles and good practice of humanitarian donorship", available at: http://www.goodhumanitariandonorship.org/gns/principles-good-practice-ghd/overview.aspx (accessed 11 January 2013).

Jahre, M., and Heigh, I. (2008), "Does the current constraints in funding promote failure in humanitarian supply chains?" Supply Chain Forum: An International Journal, Vol. 9 No. 2, pp. 44-54.

Jahre, M., and Jensen, L-M. (2010), "Coordination in humanitarian logistics through clusters", International Journal of Physical Distribution \& Logistics Management, Vol. 40 No. 8/9, pp. 657-674 .

Kent, R. (2012), "Dawn of a new global humanitarian order”, available at: http://reliefweb.int/node/471303 (accessed 12 June 2012).

Kent, R., and Burke, K. (2011), "Commercial and humanitarian engagement in crisis contexts: Current trends, future drivers”, Humanitarian Futures Program, Kings College, London. 
Kovács, G., and Spens, K.M. (2007), "Humanitarian logistics in disaster relief operations", International Journal of Physical Distribution and Logistics Management, Vol. 29 No. 12, pp. 801-819.

Kovács, G., and Spens, K.M. (2008), "Humanitarian logistics revisted”, in Arlbjørn, J.S., Halldórsson, A., Jahre, M., and Spens, K.M. (Eds), Northern Lights in Logistics \& Supply Chain Management, Copenhagen Business School Press, Copenhagen, Denmark.

Kovács , G., and Spens, K.M. (2011), "Humanitarian logistics and supply chain management. The start of a new journal", Journal of Humanitarian Logistics and Supply Chain Management, Vol. 1 No. 1, pp. 5-14.

Kunz, N., and Reiner, G. (2012), “A meta-analysis of humanitarian logistics research", Journal of Humanitarian Logistics and Supply Chain Management, Vol. 2 No. 2, pp. 148160.

Majewski, B., Navangul, K., and Heigh, I. (2010), "A Peek into the future of humanitarian logistics: Forewarned is forearmed", Supply Chain Forum: An International Journal, Vol. 11 No. 3, pp. 4-19.

Newport, J.K., and Jawahar, G.G.P. (2003), "Community participation and public awareness in disaster mitigation”, Disaster Prevention and Management, Vol. 12 No. 1, pp. 33-36.

Oloruntoba, R. (2005), "A wave of destruction and the waves of relief: issues, challenges and strategies", Disaster Prevention and Management, Vol.14 No. 4, pp. 506-521.

Perry, M. (2007), "Natural disaster management planning: A study of logistics managers responding to the tsunami", International Journal of Physical Distribution and Logistics Management, Vol. 37 No.5, pp. 409-433.

SES Queensland. (2012). "Welcome to the Queensland State Emergency Service", available at: http://www.emergency.qld.gov.au/ses/ (accessed 8 January 2013).

Stoddard, A. (2008), "International humanitarian financing: Review and comparative assessment of instrument", Report for Office of US Foreign Disaster Assistance 22 July, available at:

http://www.humanitarianoutcomes.org/pdf/HumanitarianFinancingReview2008.pdf (accessed 6 June 2012).

Tatham, P.H., and Pettit, S.J. (2010), "Transforming humanitarian logistics: the journey to supply network management", International Journal of Physical Distribution and Logistics Management, Vol. 40 No.8/9, pp. 609-622.

Teece D.J., and Pisano, G. (1994), “The dynamic capabilities of firms: An introduction”, Industrial and Corporate Change, Vol. 3 No. 3, pp. 537-556.

Thomas, A. (2003), “Why Logistics?”, Forced Migration Review, No.18, p. 4.

Thomas, A. and Kopczak, L. (2005), "From logistics to supply chain management: The path forward in the humanitarian sector", Fritz Institute, pp. 1-15, available at http://www.fritzinstitute.org/PDFs/WhitePaper/FromLogisticsto.pdf (accessed 6 June 2012). 
Tomasini, R., and Van Wassenhove, L.N. (2009), Humanitarian Logistics, Palgrave Macmillan, Basingstoke, UK.

Van Wassenhove, L.N. (2006), "Humanitarian aid logistics: supply chain management in high gear”, Journal of Operational Research Society, Vol. 57 No. 5, p. 475.

Van Wassenhove, L.N., Tomasini, R., and Stapleton, O. (2007), "Corporate responses to humanitarian disasters. The mutual benefits of private-humanitarian Cooperation", Research Report R01415-08-WG, The Conference Board INSEAD Paris.

Vohr, J.A. (2011), "Haiti disaster relief: Logistics is the operation", Military Review, July/August, pp. 76-82.

Wakolbinger, T., and Toyasaki, T. (2011), "Impacts of funding systems on humanitarian operations", in Christopher, M.G., and Tatham, P.H. (eds), Humanitarian Logistics. Meeting the Challenge of Preparing For and Responding to Disasters" Kogan Page Limited, London: pp. 33-46.

Wenger, E., and Snyder, W. (2000), "Communities of practice: The organizational frontier", Harvard Business Review, January-February, pp. 139-145.

Wenger, E. (2006), "Communities of practice: A brief introduction", available at: www.ewenger.com/theory/communities_of_practice_intro_WRD. doc (accessed August 1, 2012). 
Table 1. Actors involved in Humanitarian Disaster Response

(Source: The authors)

\begin{tabular}{|c|c|c|}
\hline Governments & $\begin{array}{l}\text { National governments from many } \\
\text { countries provide bi-lateral and } \\
\text { multi-lateral aid funding }\end{array}$ & $\begin{array}{l}\text { Focus on risk reduction, preparation and response, } \\
\text { with donations for bilateral and multilateral } \\
\text { programmes and emergency appeals often ear- } \\
\text { marked }\end{array}$ \\
\hline Donors & $\begin{array}{l}\text { International organisations (UN), } \\
\text { national governments, private } \\
\text { sector organisations, general public, } \\
\text { philanthropic individuals }\end{array}$ & $\begin{array}{l}\text { Donations often ear-marked - often have their own } \\
\text { agendas - assistance delivered by other agencies eg } \\
\text { NGOs }\end{array}$ \\
\hline $\begin{array}{l}\text { International and } \\
\text { Regional } \\
\text { Organisations } \\
\text { (Inter- } \\
\text { Governmental IGO }\end{array}$ & $\begin{array}{l}\text { UN Agencies involved in } \\
\text { humanitarian activities, } \\
\text { International banks and } \\
\text { International organisations }\end{array}$ & $\begin{array}{l}\text { Includes UN Agencies such as the World Food } \\
\text { Programme (WFP), and UN High Commissioner } \\
\text { for Refugees (UNHCR); World Bank; International } \\
\text { Federation of Red Cross and Red Crescent } \\
\text { Societies (IFRC) }\end{array}$ \\
\hline $\begin{array}{l}\text { Non-Government } \\
\text { Organisations }\end{array}$ & International/national NGOs & $\begin{array}{l}\text { Rely on funding from international organisations, } \\
\text { governments and public donations - some involved } \\
\text { in development as well as disaster response }\end{array}$ \\
\hline $\begin{array}{l}\text { National Police and } \\
\text { Armed Forces }\end{array}$ & $\begin{array}{l}\text { National police and international } \\
\text { military and armed forces }\end{array}$ & $\begin{array}{l}\text { Mobilised in early post disaster phase, life saving } \\
\text { and quick response for efficient communications, } \\
\text { medical assistance, transport - trained logisticians }\end{array}$ \\
\hline Media & Electronic and print media & $\begin{array}{l}\text { Can influence level of donations - coverage can be } \\
\text { determined by political considerations - used by } \\
\text { some NGOs to publicise their own causes }\end{array}$ \\
\hline $\begin{array}{l}\text { Commercial and } \\
\text { Private Sector } \\
\text { Organisations }\end{array}$ & $\begin{array}{l}\text { International and national } \\
\text { commercial organisations such as } \\
\text { TNT, DHL }\end{array}$ & $\begin{array}{l}\text { International organisations partner with UN } \\
\text { agencies such as WFP - Private sector Small and } \\
\text { Medium Enterprises (SMEs) - local and external - } \\
\text { part of Corporate Social Responsibility (CSR) } \\
\text { programmes }\end{array}$ \\
\hline Local Populations & $\begin{array}{l}\text { Local military, emergency services } \\
\text { and national police forces. } \\
\text { Commercial and private sector } \\
\text { organisations. Church } \\
\text { organisations. Local Government } \\
\text { Units (LGUs), General population }\end{array}$ & $\begin{array}{l}\text { First responders, involved in rescue and evacuation } \\
\text { - suffer from lack of resources particularly in } \\
\text { poorer areas }\end{array}$ \\
\hline
\end{tabular}


Figure 1. A theoretical model to Enhance Preparedness and Response to Natural Disasters in the the National Capital Region of the Republic of the Philippines

(Source: The Authors)

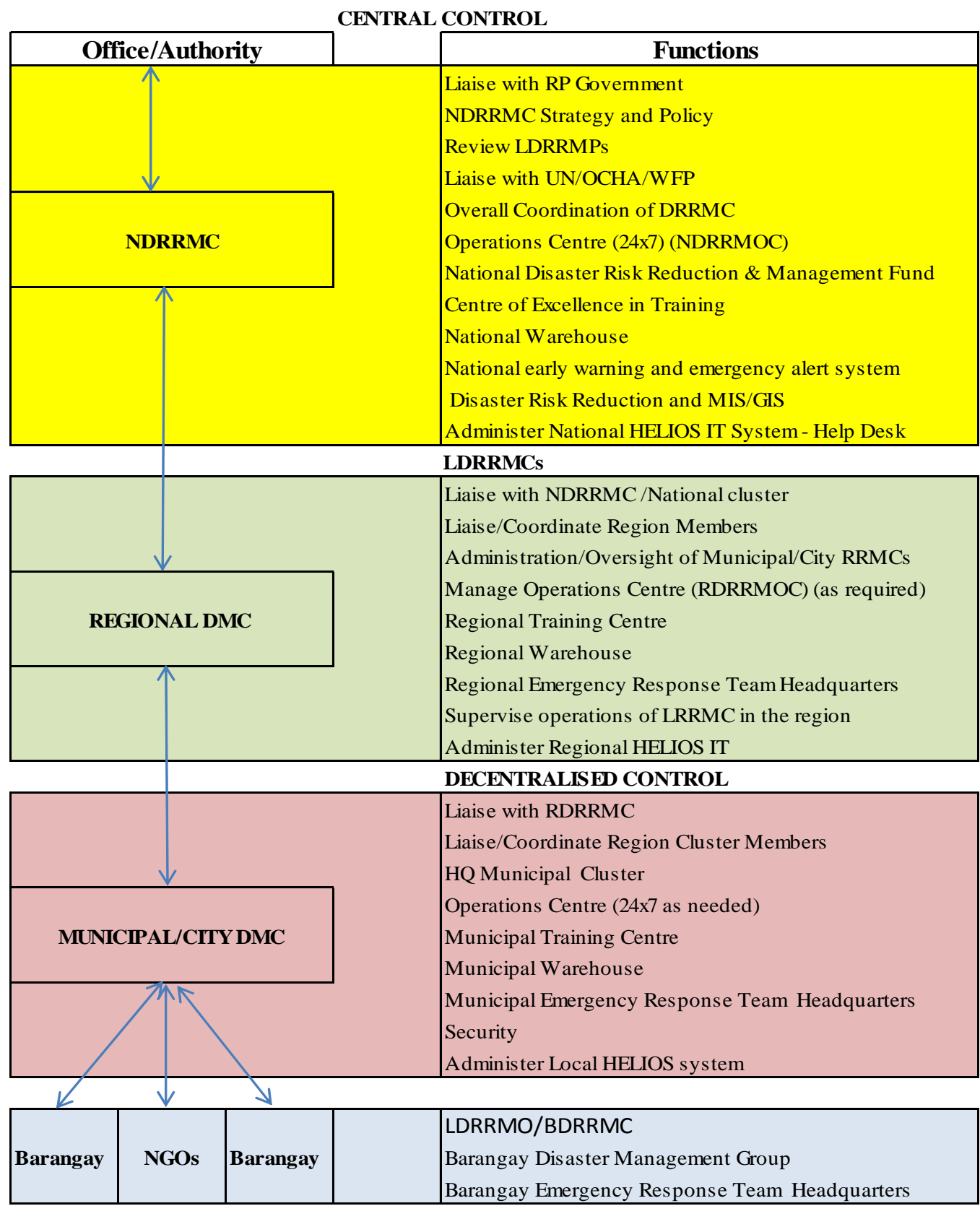

